\title{
Experiences of the Development of Parent-Adolescent Relationships among Korean Mothers
}

\author{
Hyun Young Koo \\ Professor, College of Nursing · Research Institute of Nursing Science, Daegu Catholic University, Daegu, Korea
}

Purpose: This study was conducted to explore Korean mothers' experiences of the development of parent-adolescent relationships. Methods: The participants were 18 Korean parents of adolescents. Data were collected through in-depth interviews. The main question was, "Could you tell me about your experiences of developing a relationship with your adolescent child?" The data were analyzed using Strauss and Corbin's grounded theory methodology. Results: The central phenomena of the experiences of parent-adolescent relationships among Korean mothers were "trying to reduce my expectations, but not being able to" and "having no idea where to go". The major action/interaction strategies were "putting aside my desires and adapting to my child's needs" and "waiting and seeing at a distance". The consequences included "appreciating myself and my child at the same time". Conclusion: These findings indicate that mothers tried to adapt to their children's needs and to keep their children at a distance. Their efforts were influenced by advice from friends and family members. The findings of this study emphasize specific aspects of how Korean mothers experienced the process of developing respectful relationships with their children.

Key words: Mothers; Adolescent; Parent-child relations; Qualitative research

\section{Corresponding author Hyun Young Koo \\ https://orcid.org/0000-0001-5848-2143}

College of Nursing, Daegu Catholic University,

33 Duryugongwon-ro, 17 Gil, Nam-gu, Daegu 42472, Korea

TEL +82-53-650-4829 FAX +82-53-650-4392

E-MAIL hykoo@cu.ac.kr

*This work was supported by research grants from Daegu Catholic University in 2018.

Received Jun 7, 2019 Revised Jul 1, 2019 Accepted Jul 2, 2019 (a) This is an Open Access article distributed under the terms of the Creative Commons Attribution NonCommercial License (http://creativecommons.org/licenses/by-nc/4.0/) which permits unrestricted noncommercial use, distribution, and reproduction in any medium, provided the original work is properly cited.

\section{INTRODUCTION}

Adolescence is a transitional period characterized by rapid physical growth, cognitive development, emotional instability, and psychological conflicts [1]. South Korean teenagers are under tremendous pressure to score higher on tests in a social context where the goal of education is focused on college admission, and they often experience burnout while trying to meet the sky-high expectations of their parents [2].

As adolescents start to form new interpersonal relationships, the parent-child relationship evolves from one involving unilateral caregiving and discipline by the parents into a mutually influential relationship where parents and children support each other and exchange opinions on an equal level [3]. Adolescents become increasingly independent, growing out of their childhood dependency on their parents. The role of parents is no longer to give immediate protection, but to provide support from a distance [4].

Respecting each other when making important decisions is a difficult task for both adolescents and their parents. Mothers often have different roles from fathers, as they are often the main caregivers responsible for their children, affecting their growth and development in numerous ways [5]. As children become adolescents, mothers may find it increasingly difficult to physically punish or control their children, and may feel 
frustrated when children claim that the rules and values set by their parents are unreasonable [1]. Moreover, this period may overlap with menopause and midlife crises for mothers, exacerbating family conflicts [6]. The stronger the disagreements between mothers and teenage children, the harder it may be for children to become independent and build their own identity [7].

Mothers may experience psychological instability and conflicts, as this period also corresponds to developmental changes in their own lives. They tend to send conflicting messages, as they are torn between wanting their children to be independent and simultaneously wanting them to remain dependent [6]. Parents should understand the characteristics of adolescents and apply appropriate methods to properly guide them, building a positive relationship that can help them healthily grow and develop. Meanwhile, mothers who mind their teenage children's business excessively and/or try to overprotect them are more likely to trigger anxiety in their children [8].

In this context, resources should be made available to help mothers of adolescents accept their children's developmental changes and to form positive relationships with their adolescent children, based on research on how mothers adapt to children's developmental changes and take steps to improve their relationships with their children. This study used grounded theory methodology to understand the issues that mothers experienced in rebuilding relationships with adolescent children and how they overcame such issues. The grounded theory approach is a research methodology that contemplates and conceptualizes human behavior based on symbolic interactionism [9], which is an effective way of studying processes involving change-in this case, with a focus on mothers' firsthand experiences in their relationships with teenage children. This study explored the experiences of mothers of adolescents as they developed their relationships within the context of Korean society and culture, the underlying causes of the observed phenomena, how they overcame conflicts, and which conditions encouraged or discouraged problem-solving.

The purpose of this study was to understand the issues facing Korean mothers as they tried to redefine relationships with their adolescent children and how they overcame such issues, using the grounded theory approach. The research question was "what are the issues Korean mothers experience in the course of developing a relationship with their adolescent children and how do they overcome such issues?"

\section{METHODS}

\section{Study Design}

This study was qualitative research that derived substan- tive theoretical implications from an investigation of the issues experienced by Korean mothers while developing relationships with their adolescent children and how they overcame these issues, using the grounded theory method [10].

\section{Participants}

The participants of this study were 16 mothers and two fathers of adolescent children. Parents of children from sixth grade through the freshman year in college were recruited as participants to represent the entire spectrum of adolescence.

Mothers who were willing to talk about issues in their relationships with their adolescent children and how they survived those issues were interviewed via social networks or through referrals from other interviewees.

We found that how mothers developed relationships with their adolescent children was often influenced by their husbands in various ways. Two fathers were included in the participant group due to the possibility that they may have had different experiences from those of the mothers. Two of the participants were a married pair (one mother and one father). The interview data from the fathers were compared to those obtained from the mothers in the data collection and analysis process, but were not included in the actual results, as this study focused specifically on the development of relationships between mothers and adolescents. The fathers' data were compared to identify similarities and differences from the mothers' data by cross-checking the properties and dimensions of categories and correlations in major categories.

The sociodemographic characteristics of the participants are presented in detail in Table 1.

\section{Ethical Considerations and Data Collection}

The study was conducted after obtaining approval from the Institutional Review Board (CUIRB-2018-0012) of D University. Prospective participants were provided an explanation of the purpose and methods of the study, and were notified that they were not obliged to participate and could decide to discontinue participation whenever they wanted. The participants were also informed that the interviews would be carried out individually and be recorded, that all information would be kept anonymous and confidential, and that the data would be discarded after research. In-depth interviews were carried out of participants who agreed in writing, and a small gift was provided as remuneration.

Data collection took place between October 6, 2018 and December 29, 2018. The time and place of the interview were set up via phone with prospective participants, and the interviews were held in a quiet study café, counselling room, or at 
Table 1. Sociodemographic Characteristics of Participants

$(N=18)$

\begin{tabular}{|c|c|c|c|c|c|}
\hline ID & Relation & Age & Occupation & Number of children & Children's sex (school grade) \\
\hline 1 & Mother & 48 & Telecommuter & 2 & $\begin{array}{l}\text { Boy (2nd grade of middle school), } \\
\text { Girl (6th grade of elementary school) }\end{array}$ \\
\hline 2 & Mother & 44 & Housewife & 2 & $\begin{array}{l}\text { Boy (1st grade of high school), } \\
\text { Boy (6th grade of elementary school) }\end{array}$ \\
\hline 3 & Mother & 36 & Housewife & 2 & $\begin{array}{l}\text { Girl (6th grade of elementary school), } \\
\text { Girl (6 years old) }\end{array}$ \\
\hline 4 & Mother & 42 & Office worker & 1 & Girl (1st grade of middle school) \\
\hline 5 & Mother & 45 & Housewife & 2 & $\begin{array}{l}\text { Boy (3rd grade of middle school), } \\
\text { Girl (1st grade of middle school) }\end{array}$ \\
\hline 6 & Mother & 47 & Housewife & 3 & $\begin{array}{l}\text { Boy (3rd grade of middle school), } \\
\text { Girl (1st grade of middle school), } \\
\text { Boy (4th grade of elementary school) }\end{array}$ \\
\hline 7 & Mother & 40 & Child care teacher & 2 & $\begin{array}{l}\text { Girl (2nd grade of high school), } \\
\text { Boy (3rd grade of middle school) }\end{array}$ \\
\hline 8 & Mother & 42 & Child care teacher & 2 & $\begin{array}{l}\text { Boy (2nd grade of middle school), } \\
\text { Boy (6th grade of elementary school) }\end{array}$ \\
\hline 9 & Mother & 40 & Cook & 2 & $\begin{array}{l}\text { Boy (2nd grade of middle school), } \\
\text { Girl (6th grade of elementary school) }\end{array}$ \\
\hline 10 & Mother & 46 & Housewife & 2 & $\begin{array}{l}\text { Boy (3rd grade of high school), } \\
\text { Boy (2nd grade of middle school) }\end{array}$ \\
\hline 11 & Mother & 45 & Housewife & 2 & $\begin{array}{l}\text { Girl (3rd grade of high school), } \\
\text { Girl (1st grade of middle school) }\end{array}$ \\
\hline 12 & Mother & 49 & Housewife & 2 & $\begin{array}{l}\text { Girl (3rd grade of high school), } \\
\text { Boy (3rd grade of middle school) }\end{array}$ \\
\hline 13 & Mother & 45 & Director & 1 & Boy (3rd grade of middle school) \\
\hline 14 & Mother & 43 & Housewife & 2 & $\begin{array}{l}\text { Boy (1st grade of middle school), } \\
\text { Girl (4th grade of elementary school) }\end{array}$ \\
\hline 15 & Mother & 47 & Manager & 2 & $\begin{array}{l}\text { Boy (3rd grade of high school), } \\
\text { Boy (1st grade of high school) }\end{array}$ \\
\hline 16 & Mother & 48 & Teacher & 2 & $\begin{array}{l}\text { Girl (1st grade of university), } \\
\text { Girl (3rd grade of middle school) }\end{array}$ \\
\hline 17 & Father & 52 & Office worker & 2 & $\begin{array}{l}\text { Girl (1st grade of university), } \\
\text { Girl (3rd grade of middle school) }\end{array}$ \\
\hline 18 & Father & 50 & Public official & 2 & $\begin{array}{l}\text { Girl (1st grade of high school), } \\
\text { Boy (2nd grade of middle school) }\end{array}$ \\
\hline
\end{tabular}

home, depending on what was most convenient for each participant. The interviews began with small talk and general questions, and then gradually moved on to in-depth questions.

The interview questions were developed to induce participants to talk about the process of overcoming any issues they encountered as they developed their relationships with their adolescent children, referring to the relevant literature, previous studies, and the researcher's experience. The main ques- tion was: "Could you tell me about your experiences of developing a relationship with your adolescent child?" Follow-up questions included: "Could you tell me about your experiences of the process of developing your relationship with your child?", "Could you tell me about any issues you may have experienced in your relationship with your child?", and "Could you tell me about your experiences of the process of overcoming those issues?”. 
During the interview, the researcher observed the general atmosphere of the interaction, meaningful emotional reactions, and nonverbal actions. Each interview was held for roughly 1 2 hours, once or twice for each participant. Each interview was recorded from start to finish and the content was transcribed immediately after the interview. The researcher's observations and overall impressions were recorded for reference. A follow-up interview was organized in cases where the first interview was not sufficient and/or had some parts that were unclear, and the interviews continued until there were no more new findings. Data collection was completed with theoretical saturation after the 18th participant, when the responses became repetitive and no new categories or properties were discovered.

\section{Data Analysis}

Data analysis was carried out simultaneously with data collection using Strauss and Corbin's grounded theory methodology [10]. At the open coding stage, interview recordings were reviewed multiple times, line by line, to derive concepts and create categories by understanding the mothers' experiences of developing a parent-adolescent relationship. Concepts were first derived from an analysis of the interview with the first participant, and then the properties and dimensions of categories were analyzed by comparing the similarities and differences in subsequent data. The derived concepts and categories were checked by repeatedly reviewing the interview data to confirm their validity. In the axial coding stage, the conditions, context, action/interaction strategies, and consequences related to the categories were analyzed and a paradigm model was constructed. Considering the conditions and context that shaped participants' experiences, actions, and changes therein, the relationships among major categories were confirmed and a comparative analysis was conducted. At the selective coding stage, recurrent key categories were selected and connected with other categories to form a storyline.

\section{Study Validity and Background of the Researcher}

The validity of the study was strengthened by achieving credibility, suitability, neutrality, and auditability [11]. Open questions were used to ensure that participants could express their experiences using their own words. The content was reconfirmed in the follow-up interviews, the categories were compared against the raw data, and the results were discussed with peer researchers to evaluate whether the results properly reflected the participants' experiences. Concepts were derived from the experiences of participants and data were collected until reaching theoretical saturation, after which the re- sults were shown to non-participant mothers to check the validity. The researcher tried to understand the process of how participants developed relationships with their adolescents without any subjective judgment or bias interfering with data collection and analysis. Participants' interviews were quoted word-for-word in the rest of the paper to facilitate a clear understanding of the results, and the procedures of data collection and analysis were recorded in detail.

The researcher is a professor of pediatric nursing specializing in growth, development, and health promotion, who has conducted research on the role of parents and relationship changes in adolescence. The academic and non-academic literature on the relevant topic was carefully reviewed to reinforce theoretical sensitivity.

\section{RESULTS}

The central phenomena of Korean mothers' experiences of developing relationships with their adolescent children were "trying to reduce my expectations, but not being able to", and "having no idea where to go". Ten categories, 16 subcategories, and 62 concepts were derived. The causal conditions that led to the central phenomena were "my child is my avatar", and "my child doesn't want my help anymore". The contextual conditions, representing the sociocultural context and background, were "grades mean everything" and "bearing the burden alone". The intervening condition that determined action/interaction strategies was "advice from others". Action/interaction strategies used to cope with the central phenomena were "putting aside my desires and adapting to my child's needs" and "waiting and seeing at a distance". The consequence of the action/interaction was "appreciating myself and my child at the same time" (Figure 1).

\section{Causal Conditions}

\section{1) My child is my avatar}

(1) I share my child's experience

Participants were concerned about how their children were doing at school and with friends, and shared their children's feelings when hurt, stressed out, or experiencing issues with peers and/or schoolwork.

Last year was hard for me, because I had to keep my feelings to myself. I wished the year would pass by as quickly as possible. Now we're both fine, my child and I. I never thought that there would be any chance of my child having such an issue with a friend... We had to make it right, step by step. (Participant \#1)

When my child studies for tests at school, I feel as if I 


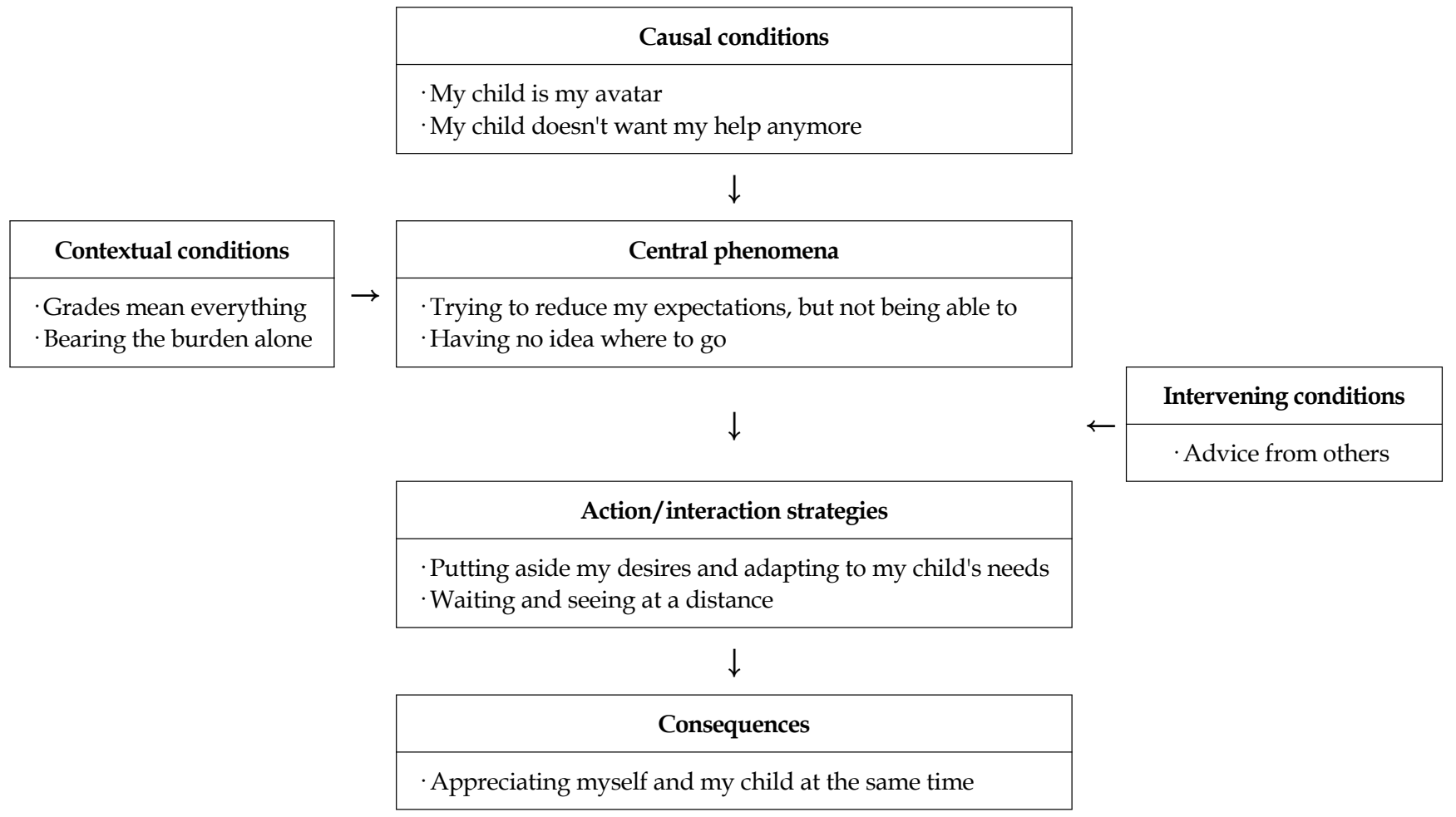

Figure 1. Paradigmatic model of Korean mothers' experiences of the development of parent-adolescent relationships.

am going through it together with him. He usually starts test preparation a month in advance, and I'm not in the position to tutor him or anything, but I try to check in with him by asking "which chapter have you studied today?" or "which subject are you studying today?" When my kid is up late studying, my friends tell me to just go to bed before him, but I just can't. When my children tell me things like "Mom, I finished my science chapter here and my math work up to this page", I tell them they did a great job and encourage them to keep going the next day. But this is all emotionally hard. I would even get sick after their tests were over, from being too nervous the whole time. (Participant \#9)

(2) My child's grades are my grades

Participants wanted to be acknowledged by others, including their husbands, for having done a good job raising their children. They identified the accomplishments of their children as their own achievements. They thought that children's grades represented their parenting efforts, using expressions like "delighted mom" and "the top-of-the-class mom”.

I was very strict with my children since their father was not there for them. I would tell them to "always be an example for other kids", even though I didn't mean to force them to do things a certain way. I made them study hard. They would stay up until $11 \mathrm{pm}$ in elementary school... That was my way of seeking compensation for my efforts to raise the kids while their father was absent. "Look, I raised them this well while you were not there." Their father told me, "You did a good job, thank you." I was so proud of myself. (Participant \#5)

I thought it would make me sad if my husband says something like "I let you do anything you would like to do for the kids' education, I provide for private tutoring, books, everything. Then how is he doing so bad?" I wanted to be acknowledged by my husband, I guess. I was obsessed with my kids. I didn't have my life, only my kids. I don't know why I was like that back then... Well, one day my kid got a 100, which truly made me a delighted mom, more than ever. (Participant \#7)

\section{(3) Vicarious pleasure}

Participants felt vicarious pleasure from providing their children with what they could not have as children. They believed that they were doing their best for the children by fulfilling their unmet childhood desires, and involved themselves in their children's studies and daily life in order to help them achieve what they had desired for themselves.

I had to take care of household chores from a young 
age. I hated that. I had no choice, though-but I didn't want my child to have do the same things. I always make her snacks from scratch. I don't make her do any household chores. I would hate for her to follow in my footsteps. I do everything for her. She will learn to do it herself one day anyway. (Participant \#3)

I wished my mom could get me a tutor or invest in my education more. It left me with a lot of resentment, not having the opportunity to thrive academically. I always felt inferior, not having graduated from a better college. That's why I am doing my best for my daughter. I'm actually jealous of her. I couldn't be happier, if I were her. I could have led a happier life had I been as academically successful as my daughter. I feel like she is living my dream. She is my avatar. (Participant \#11)

\section{2) My child doesn't want my help anymore}

\section{(1) Rebellious children}

Children started to rebel against parents' requests and to behave as they wanted when they reached puberty. They wanted to get out from their parents' control, did not like how their mothers tried to take care of them, resented their mothers, or felt excessively controlled or ashamed of receiving maternal care.

My child would raise his voice more often than when he was younger. Before, he would just say "yes", but now he often responds with things like, "I don't want to", "No", "I'll do it later", "Mom, why are you doing this?", and "why just me when my friends don't have to?" (Participant \#10)

My kid says she can only remember things I did wrong. "You didn't let me meet friends, you stifled me!" She would drive me mad by talking back to me like, "What do you expect, mom? I just can't do it.” (Participant \#7)

\section{(2) Mature children}

Participants realized that their children not only had grown up physically, but also had become mentally more mature, and were not babies anymore. Participants directly felt the impact of their children's maturation as they became more thoughtful and caring towards their mothers.

My kid would say, "Mom, you're being whiny and negatively comparing with others" in a very calm way. I get surprised how she can manage to talk this way. She's been like that since last year. I'm surprised at how deeply my kid can think. And she's right, after all. I might try to deny it by saying "No, that's not what I meant $\cdots$ ", but I'm secretly surprised at how she has grown mentally, when I always thought she was little. (Participant \#1)

The other day, I asked my kid, "Why don't you tell me anything about your friends?", and she responded "I can take care of it myself. I don't want you to be upset." She wasn't telling me about those issues because she felt like she could deal with it on her own without making me upset. (Participant \#14)

\section{Contextual Conditions}

\section{1) Grades mean everything}

(1) Social pressure for good grades

Participants agreed that academic success and school grades are crucial in Korea and that they experience social pressure to achieve those goals together with their children. Participants found private tutoring to be essential for managing their children's test scores and prioritized their children's education.

You know what the educational environment is like in Korea. My husband feels the same way about Korean education, especially as he has experience working abroad. He values studying and education more than I do. "You need to study hard, go to a good college. Only then you will have more jobs available on your career path. You need to study hard to give yourself better opportunities", he would say. (Participant \#5)

Kids are busier on Saturdays. Family gatherings are arranged around my kids' schedule, often one or two months ahead. I tell other family members when my kids will be free. Any event should be held on days when my kids are off. During midterms and finals, grandparents are not allowed to visit because it might affect the kids' studies. (Participant \#9)

\section{2) Bearing the burden alone}

\section{(1) A solitary burden}

The participants were primarily responsible for child rearing, and the children were also closer to their mothers than to their fathers. The participants often did not receive any help from their family, friends, or husbands. Husbands frequently failed to fulfill their role as fathers.

I'm a little frustrated. I rarely see my husband since he goes to work early in the morning and comes home very late. Sometimes he only sees the kids on weekends. He comes home at midnight or even later, so he can't see the kids every day. We only have time to have a conversation on weekends. He's too tired on weekdays when he's home, so I don't dare to start a conversation. He would 
tell me to just do as I like, since he doesn't get to see the kids as often. (Participant \#3)

My husband and son play together and make pranks, but they seldom have deep conversations. Like man talk, things they wouldn't tell mom $\cdots$ That just doesn't seem to happen. Too bad. (Participant \#10)

\section{Central Phenomena}

\section{1) Trying to reduce my expectations, but not being able to}

(1) Fatigue from unmet expectations

Participants expected their children to excel at school. They were disappointed when their children failed to do so and expected more even when they did well. They experienced fatigue from the repeated cycle of expectations and disappointment, but could not put aside their expectations. Participants often had conflicts with their children over school grades, smartphone use, and gaming, scolding them for playing games for too long and not studying.

I know I have to, but I just cannot let go of my expectations. My kid did very well until his second year in middle school. I was so happy about it. I guess my expectations were too high. I would say things like "why don't you read a book instead?" I know I shouldn't. He does a lot, actually. He attends many private tutoring sessions, and I know he needs room to breathe. (Participant \#7)

I even ask myself, "why am I being so greedy?" But I just couldn't let go. I invested a lot in her ever since she was young. I might have given up if her grades dropped sharply. (Participant \#11)

\section{2) Having no idea where to go}

(1) Not like it used to be

Participants felt frustrated because they did not know how to communicate well with their children. They were angry and upset towards their children for rebelling and keeping a distance from them, but were not sure how best to treat their adolescent children. Participants sometimes questioned whether their way of parenting was wrong.

I couldn't force him too much. He would make faces and frown. Although he wouldn't talk back or anything, if he frowned and expressed that he was upset, I'd be careful around him. I should probably nag him less. (Participant \#10)

I'm just trying to teach my daughter a more comfortable way to live, as someone who had gone through life a little earlier. I think I failed (sobbing). I put everything in one basket and now I think this is not the right path.
Sometimes she loses her temper and fights back, and I think, "She must have hated me for doing that. Even though I was doing it for her." (Participant \#11)

\section{Intervening Conditions}

\section{1) Advice from others}

\section{(1) Advisors}

Participants listened to advice from family members and peer mothers, who may do things differently. Participants also remembered how they were loved and trusted by their own parents.

I am not a very touchy-feely person by nature. Meanwhile, my friend has two daughters who are almost twice as big as mine. She's in middle school but still cries in her mom's arms. My friend would comfort her first before discussing the problem with her. I used to wonder how my friend could still hold and hug such a full-grown daughter, ever since she was in elementary school. Now I realize that maybe I'm wrong. I learned that it's important to stay friendly with my daughter. (Participant \#6)

I feel like I'll follow in my father's footsteps - I'll give everything to my kids and will have nothing left for myself. Having raised my own kids now, I wonder how many things my father kept to himself. Whenever I lament "I don't know why my son isn't getting better grades when he seems to have the potential", my mother reminds me of how mature my son is for his age. I should stop seeing what others have and start focusing on what my son is good at. (Participant \#12)

\section{Action/Interaction Strategies}

1) Putting aside my desires and adapting to my child's needs (1) Self-reflection

Participants reflected and regretted their communication and parenting style, tried to learn from their trials and errors, and sought better ways to behave.

I was wrong then. The times when I felt exhausted, I would feel betrayed by my daughter. I only speak from my perspective and the same goes for her. (Participant \#4)

I feel like I would have been more generous to my kids if I had acknowledged their strengths first. I always thought, "She will be perfect if she doesn't do this." I think we often clashed because of my high expectations. I should have praised my kids when they met my expectations, but I always focused on things they were not good at. (Participant \#16) 


\section{(2) Adapting to children's needs}

Participants tried to reduce their expectations for their children's academic achievement and test scores, trying to listen to their children's voices and communication. They tried to understand their children's needs and cater to them.

That day, I decided to do whatever my kid wanted. "What do you want to do?" "I want to eat sujebi." Then we would go eat it together. "Mom, let's go shopping for cosmetics!" And I would go look at cosmetics with her. She didn't even buy or wear them, she was just interested in seeing what's out there. She also wanted to wear matching clothes with me. We bought matching skirts. When My husband asked her if she was hungry after coming home that day, she goes "No, I ate everything I wanted and did everything I wanted to. I couldn't wish for more!" (Participant \#6)

Today my boy came home excited, he said something cool at a classroom meeting and the kids applauded him. I said "Wow, you are fabulous. That's an experience not everyone can have! How could you think of such an idea in the heat of the moment? I would have been too embarrassed to come up with such a good idea." He couldn't be more excited. I like to praise him in an exaggerated way on such occasions. He gets thrilled and so proud of himself. (Participant \#10)

\section{2) Waiting and seeing at a distance}

(1) Accepting children as who they are

Participants tried to accept certain character traits and circumstances of their children as they were and to embrace how their children changed as they went through puberty, rather than judging their strengths and weaknesses.

She is very different from me. I'm over 40 now but I couldn't even imagine singing or dancing in front of my parents as a child. But she likes to dance, and it's almost like she's from another planet. As I started to recognize such differences, I realized that I can't just force my way. (Participant \#4)

Just small things, like a friend intentionally knocking down her pen. It sounds like nothing, but she would say the kid hates her. For adults, it may seem like nothing, but kids get hurt so easily. For them, friends are everything. So I would just listen to her story. (Participant \#6)

(2) Wait and let their children take care of their own problems

Participants waited until their children learned on their own, giving them opportunities to choose and encouraging them to take care of themselves. They tried not to force their children to do things a certain way; instead, they turned a blind eye to certain issues, were patient, and saw how their children would deal with things.

I tried not to be too authoritative with my daughter, and she's my only daughter so we tried to be like friends. We tried to resolve any incidents smoothly. A friend of mine would ask me "why don't you make your daughter apologize to you?" But I don't want a parent-child relationship to be so strict, I'm fine if my daughter can learn from her own heart, even if she doesn't necessarily directly apologize. As she grows up, she will experience her own clashes and conflicts in her little world. I believe she will learn her lessons from those experiences. (Participant \#4)

We live in this apartment complex and I hear a lot of things from my neighbors. Like, "Oh, I saw your son going somewhere earlier." I feel like I know too much about things that might be his own private concerns. I mean, he goes to some undesirable places to hang out with his friends, and I'm willing to turn a blind eye to it, as long as it doesn't happen too often. That's what I would do these days. I mean, I did the same stuff as a kid. (Participant \#10)

\section{Consequences}

\section{1) Appreciating myself and my child at the same time}

(1) Respecting children as individuals

Participants were grateful that their children were coping well with puberty and respected them as individuals. They respected and followed their children's choices, acknowledged their abilities, and communicated with them.

My kid wanted to attend a certain private institution for math, which was too far from home in my opinion. But she insisted on it and I had to support her choice. "Mom, let me decide if it is right for me. Please send me there for now." We just have trust in each other. I try to support her decisions. After all, she has never disappointed me by following her own choice. (Participant \#4)

Seeking obedience, making them listen to my words, that's not a good way to go. We both influence and respect each other. One day my kid told me "Mom, thank you for listening to what I say. You're a good mom!" (Participant \#6)

(2) Appreciating the value of my life

Participants adapted to the changes that they and their 
adolescent children were going through, looked on the bright side, and were satisfied with their relationship with their children. They felt fulfillment by focusing on their work or trying new things out, and experienced improvements in their relationships when they focused on their own life and work.

"I failed to enter the most prestigious college, but I was lucky in other ways. I got a job at a big company during economic downturns, married your father, and had a gorgeous daughter like you. I'm blessed and happy, with nothing to worry about", I would tell my daughter, and it helps her look on the bright side of things. She seems to believe that she might experience failure sooner or later, but she will definitely be rewarded for her efforts. (Participant \#4)

I learned a lot and it was a great experience. I was very interested in children with disabilities at work. I work at a childcare facility that accepts children with disabilities. It's challenging but I like it. I believe the kids understand me. It also seems to help my children. I used to only talk about one topic with my kids. "What did you do in school today? How was lunch? What did you learn? What did you learn at tutoring?" That was all. When I stayed at home, I didn't have special things to talk about. My daily routine was the same. Now I tell my kids, "The kids at childcare are just like when you were babies. I scolded some of them because they wouldn't listen to me, but they weren't upset at all and still came to me for snuggles." I think my kids are happier with me having a job and hearing my stories. They understand what I do. (Participant \#8)

\section{Core Categories}

The core categories the researcher found for how Korean mothers developed their relationships with their adolescent children were not being able to let go of their expectations and feeling lost, "seeking the right direction".

Participants looked for vicarious satisfaction from their children, treating them as their other self and identifying their children's success as their own, but were confused when their children no longer needed them as much as they entered adolescence. Participants were faced with the burden of raising their children alone in a social context where school grades and academic achievement are disproportionately valued, were unable to let go of their high expectations, and did not know where to go. Participants learned from the advice they received from close friends and family members about parent-child relationships, looked back on their relationships with their children, listened to their children's needs, embraced their children as they were, and tried to give them a chance. They gradually made progress as their children matured into puberty, and participants with older children had made further progress. Through this process, participants were able to acknowledge their children as independent individuals and appreciate the value of their own lives.

Other participants were unable to make appropriate efforts to change their relationship with children, when they deemed their children's school achievement to be the most important factor and felt solely responsible for their children's education. They were also unable to look for ways to improve their relationships when they did not have anyone nearby to give advice or did not have the chance to learn from others about parenting and relationship-building. As a result, they could not separate themselves from their children as individuals or let go of sky-high expectations, feeling lost in terms of how to remediate their relationship with their children.

\section{DISCUSSION}

This study found that the central phenomena that Korean mothers experienced in the process of developing relationships with their adolescent children were "trying to reduce my expectations, but not being able to", and "having no idea where to go". The core category was "seeking the right direction." Participants became tired of the repeated cycle of expecting more from their children and being disappointed. They hoped that their children would excel at school and that they would study hard to get better grades. They also tried to control their children's smartphone use and gaming, and were often faced with resistance from their children. Previous studies have also suggested that schoolwork and smartphone use are major sources of conflict [12]. Mothers were concerned that the more time their children spent on smartphones and games, the less time they would spend studying, leading to lower grades. Participants were confused as their children went through puberty and questioned their parenting style. This supports the findings of previous studies [12], which suggested that the biggest challenge mothers faced as their children hit adolescence was that their parenting style did not seem effective anymore and that mothers failed to catch up with the pace of changes their children experienced. The participants in this study found it difficult to discipline their children in the same way that they had done before.

The causal conditions that led to the central phenomena were "my child is my avatar" and "my child doesn't want my help anymore". Participants shared their children's routines and suffered together, sought vicarious satisfaction through their children, recognized children's academic achievements 
as their own accomplishments, and wanted to show off. It has been reported that children with more demanding and controlling parents scored better on tests and interpreted parental control as a way of showing affection [13]. In Korea, parents and children tend to identify each other as a single entity, unlike in western cultures [14]. However, a recent study [15] suggested that children of demanding fathers engaged in less self-study and that children with more controlling parents struggled more. Teenagers experienced burnout when they were excessively anxious and worked too hard to meet their parents' high expectations [15]. Parents and children may have different desires and needs, but Korean college students responded in a survey that they tried to meet the expectations of their parents as adolescents, following their parents' desires and not their own heart [16]. Today's Korean teenagers may complain that their parents put intense pressure on them and are highly controlling, which can make it harder for parents to react properly.

The contextual conditions of the central phenomena, which reflected the sociocultural context, were "grades mean everything" and "bearing the burden alone". Participants believed in the quintessential importance of test scores and academic achievement in Korean society, and prioritized their children's studies. Academic achievement and occupation are deemed as the main criteria for measuring one's success in competitive Korean society, and test scores are a key part of teens' routines [17]. The participants were the main caregivers for their adolescent children, as well as when they were little, and they scheduled family occasions and routines around their children's study schedules. Their husbands were not able to provide much help, and failed to play a sufficient role as fathers. In light of research [18] suggesting that the more time teens spend with their fathers, the more awareness they are likely to have of equality and the more likely they are to form a positive identity, it is important that fathers pay more attention to their children's development, communicate openly, and develop a close relationship to promote healthy development of adolescents. Accordingly, fathers should be provided with appropriate training and guidelines on their role as parents so that they can understand the characteristics of adolescent development, transitions in the parent-child relationship, and how to communicate with children.

The intervening condition that determined action/interaction strategies was "advice from others". The participants observed and had conversations with other people regarding parenting styles and relationships with their children and learned from them. Previous studies have also demonstrated that the mothers of adolescents attended parenting sessions or discussed their woes with friends who were also mothers [12]. However, the participants in this study were not able to change their interaction strategies simply by lamenting their issues together with people around them. Mothers were able to alter and adjust their interaction strategies when they openly listened to other people's advice, observed how they treated their children, and learned from these experiences. Participants also remembered how they were loved and trusted by their own parents as children and wished to re-enact such behavior. Building a close emotional bond with one's parents is related to embracing oneself and forming stable interpersonal relationships [19], and positive parent-child relationships seem to be passed down across generations.

The action/interaction strategies found among participants in coping with the central phenomena were "putting aside my desires and adapting to my child's needs" and "waiting and seeing at a distance". Participants engaged in self-reflection on their parenting style and tried to listen to their children's voices, rather than insisting on their ideas. Positive and supportive parenting is crucial to fostering adolescents' healthy growth and development [20]. Warm and affectionate support from parents promotes healthy development, while authoritarian parenting may act as an impediment [21]. Adolescent children recognize parents' efforts when parents try to pay attention to their needs and support them. Existing studies have proven that children could deal with stress and issues better when they were able to openly communicate with their parents, while keeping an appropriate distance [22]. Participants also tried to accept their children as they were, patiently waited for children to learn and make choices of their own, and encouraged them from a distance. Authoritative commanding, controlling, and being excessively nosy and protective of children will likely deter the proper growth and maturity of adolescents, making them grow up to be dependent and inadaptable for school and society [23]. Adolescents felt satisfied when their parents listened to their ideas, and saw improvement in their relationships when their parents trusted them and waited for them at a distance [16]. In other words, children make efforts to improve their relationships with their parents when their parents reach out first. Practical and welldesigned education and support programs will be beneficial to help parents learn how to lead interactive communication with their adolescent children and listen to children's voices. Parents with adolescent children should practice providing opportunities for their children to be responsible so that they can learn how to set their own goals, make choices, and stick to those choices.

The consequence of action/interaction found in this study was "appreciating myself and my child at the same time". Participants recognized their children as independent individuals and respected their choices. They focused on sources of positive value in their lives and concentrated on taking care of 
themselves and their work. Mothers should understand that their relationship with children should transform from oneway parenting to a mutually supportive and respectful one and adapt to such changes [3]. Korean adolescents tend to live with their parents longer than in some other countries, and parents have a stronger influence regarding education [18], but at the same time, adolescents wished to become more independent from their parents and to keep a distance. Therefore, mothers who play the role of a main caregiver should understand that adolescent children need privacy, more time with their friends, and to make their own choices, and that such changes are part of the natural developmental process. In particular, most participants were at their own developmental stage of midlife transition, where they acknowledge and re-evaluate their life from a new perspective, ripening into a more mature adulthood [6]. Therefore, mothers of adolescents should review and adjust their role as parents, growing along with their children as they progress into their children's adolescence [24]. With this in mind, parenting education sessions should provide effective ways to help parents and adolescent children understand each other's developmental stages, as well as offering resources to support this goal.

\section{CONCLUSION}

This study was conducted with the goal of understanding the issues facing Korean mothers as they developed relationships with their adolescent children and how they overcame those issues. In-depth interviews were carried out with 16 mothers and two fathers of adolescent children, and the results were analyzed using the grounded theory method. The central phenomena were "trying to reduce my expectations, but not being able to" and "having no idea where to go". Mothers used the action/interaction strategies of "putting aside my desires and adapting to my child's needs" and "waiting and seeing at a distance" under the intervening condition of "advice from others", and they managed to "appreciate myself and my child at the same time". This study proved that Korean mothers tried to accommodate their adolescent children's needs and took the approach of waiting and seeing from a distance how their children would figure things out. It is important to provide intermediary assistance to help mothers and adolescent children develop a healthy relationship using these interaction strategies and to consider the conditions that affect them.

\section{Conflict of interest}

No existing or potential conflict of interest relevant to this article was reported.

\section{REFERENCES}

1. Cho BH, Jung OB, Yoo GH. Human development: Psycho-developmental approach. 2nd ed. Seoul: Kyomoonsa; 2004. p. 118-135.

2. Jeong YB, Chang HA. The effects of parental academic achievement pressure on academic burnout of high school students: The mediating effect of evaluative concerns perfectionism. Korean Journal of Youth Studies. 2017;24(7):167-190.

https://doi.org/10.21509/KJYS.2017.07.24.7.167

3. Schwartz SJ, Mason CA, Pantin H, Szapocznik J. Longitudinal relationships between family functioning and identity development in Hispanic adolescents: Continuity and change. The Journal of Early Adolescence. 2009;29(2):177-211. https://doi.org/10.1177/0272431608317605

4. Fosco GM, Caruthers AS, Dishion TJ. A six-year predictive test of adolescent family relationship quality and effortful control pathways to emerging adult social and emotional health. Journal of Family Psychology. 2012;26(4):565-575.

https://doi.org/10.1037/a0028873

5. Jung YH, Yang SE. A qualitative study on the self-identity development of career women: Focusing on parents-daughter relationships. Journal of Korean Home Management Association. 2011;29 (1):1-19.

6. Leifer G, Fleck E. Growth and development: Across the lifespan. 2nd ed. St Louis MO: Elsevier; 2012. p. 183-194.

7. Kim HJ, Bang HJ. The influence of maternal parenting on adolescence separation-individuation mediated by mother-adolescent conflict: The moderating effect of peer attachment. The Korean Journal of Developmental Psychology. 2008;21(4):165-187.

8. Shin MJ, Ha EH. The mediating effects of negative cognition in the relationships between mothers' overprotective parenting attitudes and adolescents anxiety. The Korean Journal of Counseling and Psychotherapy. 2010;22(2):459-477.

9. Glaser BG, Strauss AL. The discovery of grounded theory: Strategies for qualitative research. Chicago: Aldine Publishing Company; 1967. p. 15-31.

10. Strauss AL, Corbin JM. Basics of qualitative research: Grounded theory procedures and techniques. 2nd ed. Newbury Park CA: Sage Publications; 1990. p. 61-142.

11. Guba EG, Lincoln YS. Competing paradigms in qualitative research. In: Denzin NK, Lincoln YS, editors. Handbook of qualitative research. 4th ed. Thousand Oaks, CA: Sage; 1994. p. 105-117.

12. Kim AY, Park B, Kim SJ, Rhee SH, Doh HS. A qualitative study on experiences of parenthood of mothers with adolescents. Korean Journal of Youth Studies. 2017;24(8):161-193. https://doi.org/10.21509/KJYS.2017.08.24.8.161

13. Tak SY, Park YS, Kim UC. Factors influencing academic achievement of university students: With specific focus on parent-child relationship, self-efficacy, achievement motivation and hours studied. The Korean Journal of Child Education. 2007;16(1):143-154. 
14. Choi IJ. Development and validation study of the Korean parent-version of child relationship scale. Research Report. Seoul: National Youth Policy Institute; 2006 December. Report No.: 06R22.

15. Lee J, Chung H. A study on the relationships between parental achievement pressure and career aspiration: Focusing on the mediating effects of academic self-efficacy and cell phone addiction. Studies on Korean Youth. 2015;26(2):209-235.

https://doi.org/10.14816/sky.2015.26.2.209

16. Koo HY. Experiences of the development of parent-child relations among Korean college students. Child Health Nursing Research. 2018;24(4):420-433. https://doi.org/10.4094/chnr.2018.24.4.420

17. Koo HY, Kim EJ. Vocational identity and ego identity status in Korean nursing students. Asian Nursing Research. 2016;10(1):68-74. https://doi.org/10.1016/j.anr.2015.11.001

18. Kim JY. Comparative analysis of socialization environment of family between Korean and Swedish youth: With a specific focus on the positive ego-identity. Korean Journal of Youth Studies. 2010;17(8):157-176.

19. Jeon SO, Kim J. The effects of college students' recognition with their parents' sense of unity and about their parents' devotion to them on their subjective happiness and psychological well-being. Journal of Parent Education. 2016;8(4):131-147.

20. Olson DH. Commentary: Three-dimensional (3-D) circumplex model and revised scoring of FACES III. Family Process. 1991;30(1):74-79. https://doi.org/10.1111/j.1545-5300.1991.00074.x

21. Zahed Zahedani Z, Rezaee R, Yazdani Z, BagheriS, Nabeiei P. The influence of parenting style on academic achievement and career path. Journal of Advances in Medical Education and Professionalism. 2016;4(3):130-134.

22. Kim J, Lee J. The relationship between parents-adolescent affective bonding (Bu-Ja-Yu-Chin-Sung-Cheong) and self-differentiation: Mediating effects of parents-adolescent communication. Asian Journal of Education. 2014;15(3):97-120.

23. Lee YW, Kim JH, Yim SY, Chae MO, Lee HR, Oh J. An evolutionary concept analysis of helicopter parenting. Child Health Nursing Research. 2014;20(4):237-246. https://doi.org/10.4094/chnr.2014.20.4.237

24. Fadjukoff P, Pulkkinen L, Lyyra AL, Kokko K. Parental identity and its relation to parenting and psychological functioning in middle age. Parenting, Science and Practice. 2016;16(2):87-107. https://doi.org/10.1080/15295192.2016.1134989 